Frances M. Boyle*, Dell Horey, Julie H. Dean, Aditi Lohan, Philippa Middleton and Vicki Flenady

\title{
Perinatal bereavement care during COVID-19 in Australian maternity settings
}

https://doi.org/10.1515/jpm-2021-0441

Received August 31, 2021; accepted February 1, 2022;

published online February 23, 2022

\section{Abstract}

Objectives: Perinatal bereavement care is a complex area of practice. The COVID-19 pandemic led to reconfiguration of maternity and perinatal bereavement care services. This study explores Australian health care providers' perspectives of the impact of COVID-19 on the provision of respectful and supportive care following stillbirth or neonatal death.

Methods: Members of a perinatal bereavement care network were consulted at the commencement of the pandemic in Australia using an online feedback form. Respondents provided ratings and free-text comments on the impact of COVID-19 on implementation of 49 recommendations contained in the Perinatal Society of Australia and New Zealand/Stillbirth Centre of Research Clinical Practice Guideline for Respectful and Supportive Perinatal Bereavement Care.

Results: Responses were received from 35 health care providers who provided perinatal bereavement care in clinical settings or through support organisations in Australia. Major impacts of COVID-19 were reported for 8 of 49 guideline recommendations. Impacts included

*Corresponding author: Assoc. Prof. Frances M. Boyle, Institute for Social Science Research, Long Pocket Precinct, 80 Meiers Road, Indooroopilly, Brisbane, QLD 4068, Australia, Phone: +61 73346 7471, E-mail: f.boyle@uq.edu.au

Dell Horey, Centre of Research Excellence in Stillbirth, Mater Research Institute, The University of Queensland, Brisbane, Australia; and La Trobe University, Melbourne, Australia

Julie H. Dean and Aditi Lohan, Institute for Social Science Research, The University of Queensland, Brisbane, Australia; and Centre of Research Excellence in Stillbirth, Mater Research Institute, The University of Queensland, Brisbane, Australia

Philippa Middleton, Centre of Research Excellence in Stillbirth, Mater Research Institute, The University of Queensland, Brisbane, Australia; and South Australian Health and Medical Research Institute, Adelaide, South Australia, Australia

Vicki Flenady, Centre of Research Excellence in Stillbirth, Mater Research Institute, The University of Queensland, Brisbane, Australia reduced: support for mothers due to visitor restrictions; availability of cultural and spiritual support and interpreters; involvement of support people in decision-making; options for memory-making and commemorative rituals; and staff training and supervision. Adaptations to minimise impacts included virtual consultations, online staff training, use of cold cots, and increased staff support for memory-making.

Conclusions: Health care providers encounter substantial challenges as they strive to implement best practice perinatal bereavement care in pandemic conditions. Some practice adaptations developed during the COVID-19 pandemic could benefit parents; however, evaluation of their effectiveness and acceptability is needed.

Keywords: bereavement care; COVID-19; neonatal death; stillbirth.

\section{Introduction}

The complex area of perinatal bereavement care faces many further challenges with the COVID-19 pandemic as maternity services reconfigure to contain the spread of the virus. In Australia, which fared favourably in comparison to many other developed nations, COVID-19 restrictions have varied in each state and territory depending on local case numbers; been timelimited; and subject to continual local, regional, and national change [1]. Although populations in some states and territories went onto have relatively unrestricted lives once the national six-week lockdown enforced earlier in the pandemic was over, wider system and process changes have resulted including, reduction in antenatal appointments, adoption of virtual care practices, and limited face-to-face contact [2, 3]. Postnatal care and support have been disrupted by physical distancing restrictions, border closures, travel bans, and quarantine measures that increased isolation and decreased access to social networks. COVID-19 related changes to maternity services have led to reports from women and their partners of reduced support and feeling isolated, stressed, anxious, fearful and sad [3-7]. 
Perinatal loss has both short- and long-term psychological and social consequences for families [8-10], that may be intensified and compounded by physical and social distancing restrictions during the current pandemic. These restrictions impeded access to family and social networks affecting emotional support and to rituals such as funerals, further hampering grief processes and exacerbating severe grief responses [11]. Health professionals can make a positive difference to grief outcomes for families who experience stillbirth. Studies consistently link parents' grief intensity with the quality of care received after their baby's death [12, 13]. It is vital that essential components of perinatal bereavement care are not lost during the pandemic to avoid exacerbating adverse outcomes such as social isolation and disenfranchised grief, already too frequent in stillbirth experiences [10]. There are indications that maternal and fetal outcomes have worsened globally, including an increase in perinatal mortality during the COVID-19 pandemic [14], making the provision of sensitive and optimal bereavement care even more pertinent and urgent. To date, there appears to be no published research on the impact of COVID-19 on perinatal bereavement, though reports from multiple sources confirm the high need for both formal and informal support at this highly distressing time $[15,16]$.

The Perinatal Society of Australia and New Zealand (PSANZ) and the Stillbirth Centre of Research Excellence (Stillbirth CRE) developed a Clinical Practice Guideline [17] incorporating a section devoted to Respectful and Supportive Perinatal Bereavement Care (the Bereavement Care Guideline) based on review of research and consultation with a Bereavement Care Guideline Update Group representing bereaved parent support organisations, clinicians, policy makers and researchers. The Bereavement Care Guideline was also informed by the Lancet's Ending Preventable Stillbirths Series [10,17], the largest source of international data of parent-reported bereavement care practices. The 49 guideline recommendations are organised using a framework (the PSANZ/CRE Bereavement Care Framework) that reflects five overarching goals of care: good communication; shared decision-making; recognition of parenthood; effective support; and organisational response [18]. This paper aims to report care providers' perspectives of the impact of COVID-19 on implementing respectful and supportive perinatal bereavement care and practice changes that have ensued.

\section{Subjects and methods}

Following completion of the Bereavement Care Guideline in 2019, 67 members of the Bereavement Care Guideline Update Group were invited to remain part of the Stillbirth CRE's perinatal bereavement care network to share updates on relevant ongoing projects. In April 2020, we again consulted this expert group about the impact of COVID-19 restrictions on the implementation of best practice perinatal bereavement care. The consultation involved two parts: ratings of impact on each of the 49 guideline recommendations and open-ended responses to describe the types of change that occurred.

The consultation process used an online feedback form developed using Checkbox software (http://www.checkbox.com) and asked about COVID-19 related adaptations to the 49 guideline recommendations using a five-point scale (1="no change"; $5=$ "major change"; or "not applicable" for recommendations not relevant to their role or organisation). Free-text comments were invited for each recommendation. The survey, which took approximately $25 \mathrm{~min}$ to complete, was open for 16 days from the 22 April, 2020. A reminder was sent after the first week.

\section{Ethical approval}

The local Institutional Review Board (Mater Misericordiae Ltd Human Research Ethics Committee) deemed the study exempt from review.

\section{Data collection and analysis}

Response frequencies were calculated for 48 recommendations (data were unavailable for 1 recommendation). Two authors (DH, FB) independently reviewed the frequencies and free-text responses to each recommendation and categorised these as either "no change", "minor change" or "major change". Disagreements were resolved by consensus and justification for determinations recorded. These were shared with all authors for confirmation.

The free-text responses were also collated to identify common challenges across all goals of care. Impacts and adaptions associated with these challenges were identified and tabulated. A core outcome set was not available for this study.

\section{Results}

Thirty-five responses (52\%) were returned. Most respondents actively provided care either in clinical settings $(n=29)$ or through bereavement support organisations $(n=2)$; the remainder were active perinatal bereavement researchers $(n=4)$. Changes in practice due to COVID-19 were reported in all five goals of care: 16 recommendations were deemed to have had no change; 26 had minor change; and 8 had major change. (Supplementary Table 1 provides the full list of recommendations and their categorisation.)

Although some core elements of perinatal bereavement care seemed largely unaffected, minimising the 
impact and restrictions of COVID-19 for families who had experienced stillbirth or neonatal death while maintaining essential public health safety measures presented challenges. Major changes were reported for recommendations across all goals of care. The recommendations for bereavement care that were most affected, with accompanying illustrative comments from respondents, are shown in Table 1. These changes were largely to reduce potential exposure by limiting numbers (Recommendations 2, 19, 32 and 40) and to extend services and training by shifting to telehealth (Recommendation 9) and to online (Recommendation 43). However, as described below, their effects were pervasive with the potential to undermine the care parents received.

\section{Impacts of COVID-19 on perinatal bereavement care practice}

\section{Good communication}

Changes to how care providers interacted with parents created conditions for communication that were less than ideal during all aspects of perinatal loss. Restricted access to support people including partners and extended family often meant communicating with parents separately, including when breaking bad news. Examples were given of women being alone when a stillbirth was diagnosed, and support persons being contacted by phone during the consultation. Advocacy efforts for women to have a

Table 1: Major changes in perinatal bereavement care practices due to COVID-19.

\section{Respectful and supportive perinatal bereavement care domains and Illustrative comments} recommendations $^{\mathrm{a}}$

\section{Good communication}

2. Include both parents in communication and decision making, if appropriate, and ask if they wish to have a support person present. Acknowledge different grief responses and support parents to express their emotions and concerns.
"We are allowing only one visitor to be with the woman at appointments and at time of admission. In the setting of additional support persons being present we are utilising IT capability to facilitate this. This can be problematic in the setting of access to technology, geographical location \& language barriers".

"Consideration needs to be given about how to involve fathers, and other supports when they may not have been as present in hospital visits etc in the lead up to the problem. This may mean that additional time is required to support them as they make sense of the situation".

"Gatherings of the extended family, community, and religious and

9. Provide culturally safe care by:

cultural services to farewell the baby cannot currently take place

under Covid-19 lockdown."

"Interpreting services are limited to telephone services. Religious recognising that diversity exists within cultural groups and bet individuals

and cultural support provided by pastoral care workers in hospitals are being viewed as non-essential during this time, in some cases spiritual needs and facilitating requests where possible these families may not be seen by their pastoral care supporters. Visitors will be restricted limiting the cultural/religious support able tural needs if the parents wish

to be provided by their chosen people".

- Determining with the parents whether an interpreter is needed and, if so, engage an accredited interpreter (some women may not wish to have a male interpreter)

"Limitations with accessing face to face interpreters on occasions. Difficulty with having a phone interpreter as the linkage with

- Being aware of particular needs of vulnerable groups who may have consultations". a history of trauma and loss

10. Identify an appropriate space for breaking bad news and all subsequent discussions with parents. Ideally, these spaces should be:

- Private and quiet

- Conducive to unrushed and uninterrupted time

- Separate from other pregnant women and newborn babies

- Suitable for extended family to gather

- Free of items or equipment that could be confronting or upsetting to bereaved parents
"The appropriateness of the space is determined by the need for protection from COVID-19. The extended family cannot gather. However, as there are no visitors allowed for anyone under the current conditions, all areas are private and quiet".

"Break bad news in ultrasound department - limited to one family member being present and no children - no allowance for extended family to gather". 
Table 1: (continued)

\section{Respectful and supportive perinatal bereavement care domains and Illustrative comments recommendations $^{\mathrm{a}}$}

\section{Shared decision-making}

19. Ask whether parents want others to be involved in decision making (e.g., family members, other support persons, community elders or spiritual leaders) while also letting parents have time to themselves.

\section{Recognition of parenthood}

32. Ensure that all parents are offered (on more than one occasion):

- Opportunities to spend time with their baby, including taking the baby home or to another place important to the family.

- Photographs that tell the story of their baby, including: the labour and birth; photographs of their baby, themselves and others with their baby; and, in the case of a multiple birth, photographs of the babies together (including any surviving babies). Advise parents of any free photography service for bereaved parents.

"Agreed but this can only be done within the confines of social distancing and number rules. Thus, these may need to be taken into account and arranged by teleconference. This could be easily arranged if need be. The new normal post COVID will be more reliance on teleheath. Patients and health care workers will need to adapt to this and there definitely are some advantages with more people being able to be involved if need be".

"This is a more challenging one through COVID. Visitations and restrictions can impact this and it will be important to consider using facetime or skype or other platforms to include support persons. It will be important health professional take the lead on how to offer and implement this as families may not be tech savvy and will need support”.

"Many of these activities may be restricted or limited. They may not be able to leave self-isolation, or enter a high-risk zone, so may not be able to take the baby anywhere or go anywhere themselves. Free photography service may not be offered or available Opportunities to involve siblings and other family member may not exist. Commemorative rituals may be limited or not offered."

"Unfortunately, there is a limit to the amount of people able to be involved in seeing the baby in hospital. If the mother has one support

- Tangible mementoes of the baby (e.g., identification tags, cot cards, lock of hair, hand and footprints).

- Opportunities to involve siblings and other family members. person, she is not able to bring in siblings or other family members". "Unfortunately, heartfelt photographers are no longer able to come in due to Covid19. So taking of photos falls to staff and parents.

- Opportunities for commemorative rituals such as naming ceremony, blessing or baptism.

\section{Effective support}

40. Offer all parents a follow-up review meeting held within 12 weeks of "This is maybe the most challenging aspect of bereavement care. the baby's death, led by a health care professional who is experienced in Given closure of clinics it can be very difficult to find follow up spots providing feedback to parents, known to the parents where relevant, and for review-meetings. Alternatives are phone/telehealth able to address the clinical and emotional aspects of their baby's death. Recognise the importance of follow-up meetings for parents:

consultations but often after 12 weeks given only limited clinic spots available".

- Provide parents with clear verbal and written details of the process "Only offering phone consultations, which can be limited to see body for follow-up appointments - Ensure all available results are assembled and provide information loss". about any delays or interim results

- Address implications for future pregnancies, including recommendations for pre-conception and maternity care

Organisational response

43. Training and support of staff is critical for the delivery of best practice perinatal bereavement care:

- All health care professionals in maternity settings should complete the IMproving Perinatal Mortality Review and Outcomes Via Education (IMPROVE) Workshops educational program or other training in perinatal bereavement care that meets appropriate standards, reflects current evidence, and addresses relevant local policies language and get a real feel for how the parents are going post their

"Allow this to take place as a telehealth conference. This is not only a great practice through COVID but can alleviate anxiety the parents may face in returning to the hospital setting".

“Training programmes are essential ... However, at present many perinatal and education meetings are cancelled or postponed and are only now beginning to be re-instituted. These could be done via Microsoft Teams or other platforms and we will certainly be starting these important teaching sessions soon".

"Training is non-essential and will not be occurring during COVID-19 times. Support to staff will be provided only using social distancing

- Formal and peer support should be readily available for health care professionals working with perinatal death

verbal communication. Staff numbers may be reduced and precepting, mentoring, supervision may not be available". 
Table 1: (continued)

\begin{tabular}{|c|c|}
\hline $\begin{array}{l}\text { Respectful and supportive perinatal bereavement care domains and } \\
\text { recommendations }{ }^{\mathrm{a}}\end{array}$ & Illustrative comments \\
\hline $\begin{array}{l}\text { - Mentoring, supervision and specialist training should be supported } \\
\text { to build capacity, sustainability and excellence in perinatal } \\
\text { bereavement care } \\
\text { - Opportunities should be provided for students and new graduates to } \\
\text { gain appropriate training and mentoring in perinatal bereavement } \\
\text { care }\end{array}$ & $\begin{array}{l}\text { "No face-to-face training available. Staff do have access to online } \\
\text { training where available or webinars". }\end{array}$ \\
\hline $\begin{array}{l}\text { 47. Establish commemorative rituals, such as an annual Remembrance } \\
\text { Service, for parents whose babies have died. }\end{array}$ & $\begin{array}{l}\text { "We do this yearly in October and this year's services will need to be } \\
\text { arranged depending on the severity of the COVID-19 scenario. There } \\
\text { are, however, many other ways of remembering that could involve } \\
\text { social distancing and social media/video platforms. Sometimes } \\
\text { these may be more powerful than individual poorly attended face to } \\
\text { face services". } \\
\text { "All Remembrance or memorial services are currently on hold; this is } \\
\text { where some parents struggle for closure". }\end{array}$ \\
\hline
\end{tabular}

${ }^{a}$ PSANZ/Stillbirth CRE Clinical Practice Guideline for Care Around Stillbirth and Neonatal Death https://stillbirthcre.org.au/wp-content/ uploads/2021/03/Section-3-Full-bereavement-care-guideline3.pdf.

support person stay with them during their loss experience were described.

The most notable change was the rapid shift from faceto-face to remote forms of communication. Despite some initial "teething issues with technology", staff had quickly acquired skills and systems to accommodate these consultations. Telehealth was generally viewed as acceptable, useful and in some instances preferred by some parents with the advantage of more people being able to be involved where needed. However, it was important to triage and assess families to enable face-to-face support where required and to recognise challenges of telehealth for both parents and care providers including differential access to Internet or appropriate devices, lack of technical knowledge or skills, and limited access to non-verbal cues and body language.

Personal protective equipment (PPE), including surgical masks, impeded face-to-face communication, nonverbal communication and expressions of empathy. For one respondent: "the hardest thing is not being able to be physical - like a touch to a patient's hand when they are grieving. The social distancing has been the hardest part". Strategies such as repetition and clarification were among the strategies used to enhance clarity of communication. Language barriers and hearing or speech impairment, required particular attention.

Suitable spaces for sensitive conversations were less often available due to hospital layout changes. Attempts were made to allocate dedicated space to allow safe relating, involvement of extended family where possible, and the use of virtual platforms. One respondent noted that a "quieter" hospital environment had increased opportunities for privacy.
These changes had particular consequences for culturally safe bereavement care. Spaces for extended family to gather and opportunities for cultural and spiritual practices were limited and challenges of ensuring appropriate use of remote interpreter services were highlighted.

\section{Shared decision-making}

Facilitating support for important and time-sensitive decisions, such as those related to timing and mode of birth, memory-making and interacting with the baby, and consent for autopsy or other investigations presented new challenges. As one respondent said: "Support persons are limited to one, whilst many families will have a team or community of decision makers". In contrast, limited involvement of others was at times viewed positively as reduced number of family members present may give parents greater autonomy to express their needs and preferences.

Also affected were timeframes for some decisions, the options available, and opportunities to revisit decisions made. For example, in some facilities restrictions meant that it was not possible for the baby to be returned to the parents' room once taken to the mortuary or other isolation room. Cold cots took on further importance in giving parents time to make decisions about time spent and interactions with their baby. Ensuring that all staff had clear and consistent information about parents' decisions and understanding that these decisions could change became increasingly important. 


\section{Recognition of parenthood}

Opportunities for memory-making and spending time with the baby were curtailed. Visitor restrictions meant that family members, including siblings and grandparents, were not able to meet the baby. Access to photographers and other memory-making activities such as bathing rituals and creation of hand and foot casts was restricted and the option for parents to take their baby home or to another place important to the family was often not available. Respondents described efforts to support parents to make memories including spending time with the baby and taking on the role of photographer for the family. Collection of tangible mementoes was largely unaffected.

Commemorative and funeral rituals were limited by COVID-19 restrictions with limits on numbers allowed to attend face-to-face services. Providing families with informational resources regarding options for commemorative events and funeral services, including those developed by parent support organisations was important.

\section{Effective support}

Disruptions to follow-up review meetings with parents within 12 weeks of their baby's death were frequently noted. Traditionally held face-to-face, follow-up meetings had been moved to telehealth. Telehealth, the use of phone or video for health care consultations, was offered differently across facilities. Different video telehealth platforms were being trialled, but in some settings "phone calls (without video options) remain the mainstay". One respondent described these meetings as "maybe the most challenging aspect of bereavement care" with others noting that an absence of non-verbal cues limited their ability to "get a real feel for how the parents are going post their loss". The potential for telehealth to diminish perceived transparency was also raised.

Benefits were identified, including alleviation of anxiety that parents may face in returning to the hospital setting, the support and sense of safety offered by their home environment, and the inclusion of extended networks if requested.

\section{Organisational response}

Staff training, mentoring and peer support activities had largely been paused. Perinatal bereavement care training had become "non-essential" with the focus of staff training shifted to COVID-19 while physical distancing requirements precluded most face-to-face training and professional development opportunities. Some organisations had responded by offering or encouraging staff to take up online training, including the national IMPROVE training program in Australia and mentoring sessions through virtual platforms.

Hospital-led remembrance services had been suspended or deferred. Some organisations had adapted by pivoting to online events with potential benefits including larger attendance numbers due to improved access for some families. Opportunities for joint services to be conducted with other organisations were also considered.

Table 2 summarises the consequences for perinatal bereavement care resulting from these COVID-19 related challenges and shows how four specific challenges from the COVID-19 pandemic (physical distancing and density requirements; use of PPE; reduced face-to-face care; and public health restrictions) have affected goals and recommendations for perinatal bereavement care. Adaptations that have been, or could be made or strengthened, are presented.

Good communication was affected by the need to use PPE, with impacts on both verbal and non-verbal communication. The changes to physical distancing and density requirements also affected communication through the loss of support people, a consequence of hospital visitor restrictions and changes to hospital layouts, affecting the capacity and location of suitably sized spaces. These changes also limited the involvement of others in decisionmaking (shared decision-making goal) and reduced opportunities to introduce the baby to others and to make memories (acknowledgement of parenthood goal).

The shift to telehealth was a common impact of the need to reduce face-to-face care and was also associated with the impacts on shared decision-making and effective support. The overall public health restrictions meant that commemorative and funeral rituals were limited or unavailable (acknowledgment of parenthood goal). For organisations, these restrictions meant a shift in focus to the public health emergency and reconfiguring service resources.

Some longer-term adaptations are likely to continue including the ongoing use of telehealth, and changes that facilitate the ease of parent access to their baby, such as the routine use of cold cots.

\section{Discussion}

Maternity and perinatal bereavement care services have undergone much change due to COVID-19. Our findings point to challenges as well as adaptations and innovations 
Table 2: Challenges, consequences and adaptations for perinatal bereavement care arising from COVID-19 public health measures.

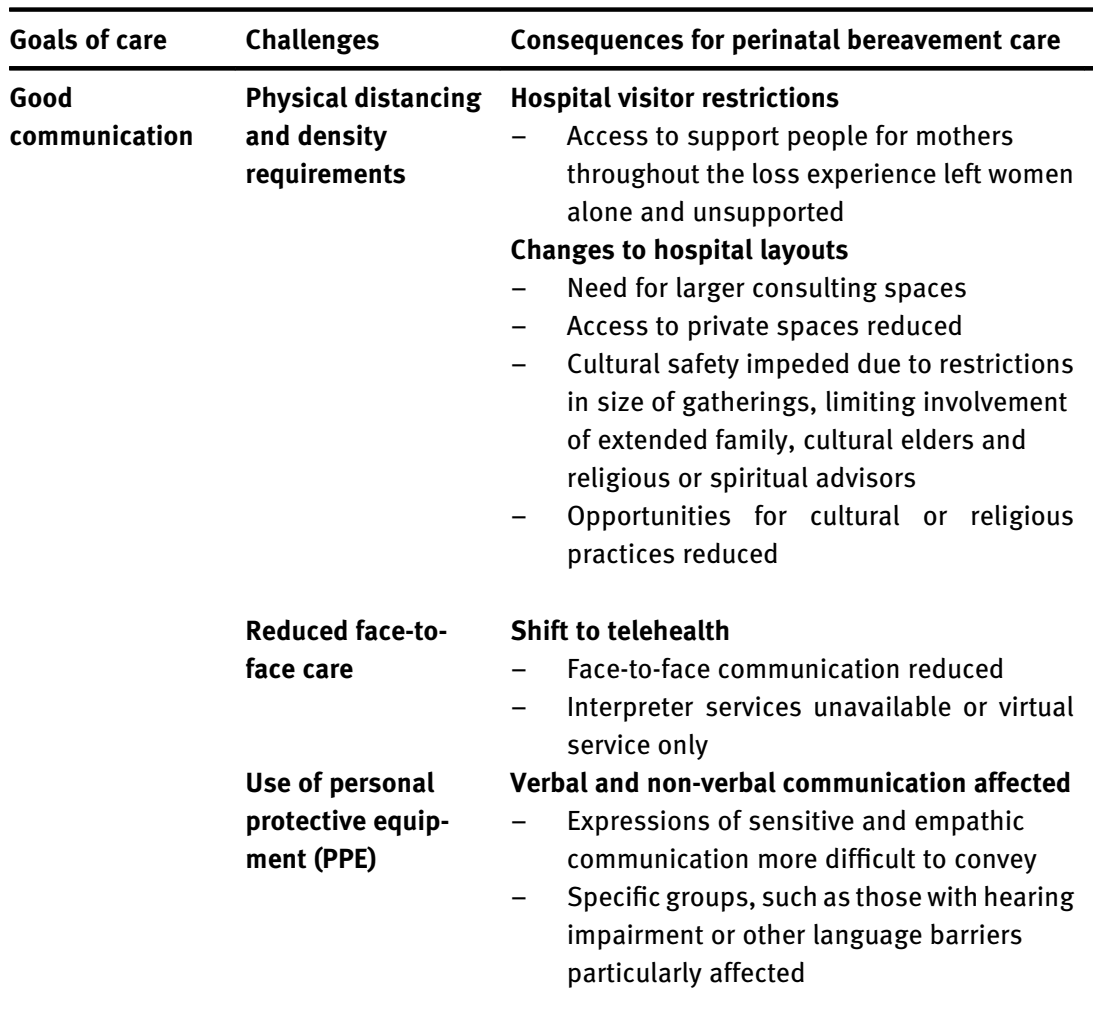

\begin{tabular}{|c|c|c|}
\hline \multirow[t]{3}{*}{$\begin{array}{l}\text { Shared decision- } \\
\text { making }\end{array}$} & $\begin{array}{l}\text { Physical distancing } \\
\text { and density }\end{array}$ & $\begin{array}{l}\text { Limited involvement of others in decision- } \\
\text { making }\end{array}$ \\
\hline & requirements & $\begin{array}{l}\text { - Decision-making support for crucial and } \\
\text { time-sensitive decisions reduced } \\
\text { - Involvement of others in decision-making } \\
\text { limited and more complex to facilitate } \\
\text { - Opportunities for parents to revisit de- } \\
\text { cisions reduced including options related } \\
\text { to seeing baby }\end{array}$ \\
\hline & $\begin{array}{l}\text { Reduced face-to- } \\
\text { face care }\end{array}$ & $\begin{array}{l}\text { Shift to telehealth } \\
\text { - } \quad \text { Reliance on virtual forms of communication } \\
\quad \text { for decision-making support }\end{array}$ \\
\hline
\end{tabular}

Recognition of parenthood
Physical distancing Loss of opportunities to introduce baby to and density requirements

Public health restrictions others unable to meet baby

Loss of opportunities for memory-making photography, hand and foot casts curtailed
Adaptations

- Virtual forms of communication (e.g., telephone, videoconferencing) adopted

Hospital visitations on compassionate grounds advocated

- Dedicated room or space allocated for families includes capacity for virtual platforms to involve extended family and other support people Consultation spaces re-arranged to allow safe distancing where possible

- Facilitation of cultural interventions via telehealth

- Chaplaincy and spiritual care services developed or arranged to meet parent requests

- Protocols, spaces and training for telehealth and hybrid services in development including interpreter services

Triage process for families to assess need for face-to-face consultation

- Virtual communication with family members and interpreters facilitated

- Strategies to enhance communication including repetition and clarification

- Professional development training in providing bereavement care when using PPE

- Use of telehealth to include extended networks

Proactive strategies to facilitate parents to revisit decisions

Availability of cold cots ensured to extend time for decision-making

- Protocols and training for shared decision-making in telehealth and hybrid service environments

- Additional health professional skills to facilitate shared decision-making in telehealth and/or hybrid environments

- Technologies implemented to involve significant others

- Family members, including siblings and Available memory-making practices reinforced, including staff sharing responsibility for photographs and other activities grandparents, and other support persons

- Memory-making options restricted including loss of access to professional

- Cultural practices such as ritual washing

- Taking the baby to other places restricted including to and from mortuary and home Impact on commemorative and funeral rituals
Alternative commemorative rituals trialled including online approaches 
Table 2: (continued)

\begin{tabular}{|c|c|c|c|}
\hline Goals of care & Challenges & Consequences for perinatal bereavement care & Adaptations \\
\hline \multirow[b]{2}{*}{ Effective support } & \multirow[b]{2}{*}{$\begin{array}{l}\text { Reduced face-to- } \\
\text { face care }\end{array}$} & $\begin{array}{l}\text { - } \begin{array}{l}\text { Funeral practices changed to meet physical } \\
\text { distancing requirements and restrictions }\end{array} \\
\text { on attendance numbers } \\
\text { - } \quad \text { Commemorative rituals deferred }\end{array}$ & $\begin{array}{l}\text { - Additional informational resources devel- } \\
\text { oped to assist parents with topics related to } \\
\text { funerals and commemorative rituals during } \\
\text { COVID-19 }\end{array}$ \\
\hline & & $\begin{array}{l}\text { Shift to telehealth } \\
\text { - Access to community support including } \\
\text { midwife home visits, face-to-face support } \\
\text { groups, face-to-face reviews and health } \\
\text { appointments reduced or removed }\end{array}$ & $\begin{array}{l}\text { - Telehealth used for follow-up review } \\
\text { meetings } \\
\text { - } \begin{array}{l}\text { Online information and support options } \\
\text { developed by parent organisations and other } \\
\text { agencies }\end{array}\end{array}$ \\
\hline \multirow[t]{5}{*}{$\begin{array}{l}\text { Organisational } \\
\text { response }\end{array}$} & \multirow[t]{5}{*}{$\begin{array}{l}\text { Public health } \\
\text { restrictions }\end{array}$} & $\begin{array}{l}\text { Public health emergency focus } \\
\text { - Shift to telehealth service delivery }\end{array}$ & $\begin{array}{l}\text { Telehealth resources and protocols } \\
\text { developed }\end{array}$ \\
\hline & & 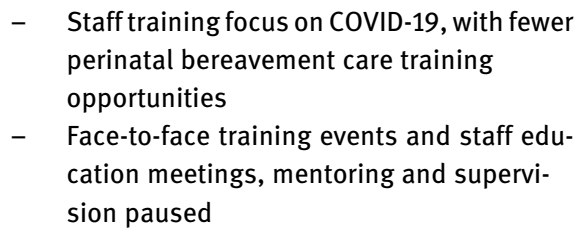 & $\begin{array}{l}\text { - Online staff training in bereavement care } \\
\text { developed } \\
\text { - } \quad \text { Mentoring sessions offered through virtual } \\
\text { platforms } \\
\text { - Planning for ongoing telehealth and hybrid } \\
\text { service provision }\end{array}$ \\
\hline & & $\begin{array}{l}\text { - Annual face to face remembrance services } \\
\text { suspended by hospitals }\end{array}$ & $\begin{array}{l}\text { - Remembrance services available through } \\
\text { virtual platforms with potential for collabo- }\end{array}$ \\
\hline & & $\begin{array}{l}\text { Reconfiguration of service resources } \\
-\quad \text { Incorporation of telehealth and other vir- } \\
\text { tual services }\end{array}$ & \\
\hline & & - Changes to ward layouts and other spaces & \\
\hline
\end{tabular}

that have been made to uphold key principles of respectful and supportive perinatal bereavement care.

The impact on specific bereavement care practices varied, and not all settings experienced the same challenges. Reassuringly, some core elements of bereavement were not affected. It was also apparent that some changes in care could have either positive or negative consequences for different people. However, of concern are a number of changes that may adversely affect longterm adjustment to grief, including lack of access to formal and informal support networks for bereaved families, fewer opportunities to revisit decisions and for memorymaking, including for others to meet the baby, impact on commemorative rituals and funerals, and on staff training opportunities. Many of the changes we report are consistent with the views of 805 practitioners concerning bereavement care during COVID-19 in UK and Ireland [19] where finding new ways to provide optimal care for families and navigating the complexities of altered practices and interactions were central themes.

Perinatal bereavement care providers have risen to these challenges by taking on new roles, learning new skills and adapting to new ways of working. Medicaresubsidised [Medicare is the government-funded universal health insurance scheme in Australia] telehealth services (phone and video consultations) have significantly expanded in Australia, and practices have embraced this mode of communication [20]. Telehealth was used to respond to many challenges while caring for bereaved families. These include involvement of support networks, shared decision-making and ensuring provision of culturally appropriate services. Restrictions on funerals and commemorative events have resulted in a rapid response by parent support organisations to provide online services and resources to support families. Follow-up review meetings with parents are also increasingly being conducted online, and so is staff training and development. Telehealth platforms may be preferred by some parents and clinicians as an alternative to face to face support as it enhances access to care of support networks and may help to reduce anxiety about returning to the hospital setting for follow-up appointments.

These service innovations may perhaps be sustained after the pandemic; however further evidence is needed regarding the efficacy of telehealth and other online practices in supporting bereaved families before routine integration into bereavement care settings. Further, staff professional development in strategies to optimise telehealth communication, for example in making adjustments to the expression of empathy and sensitive communication may be a useful investment for staff training. Telehealth may be particularly challenging for specific groups such as when language barriers are present or when families are in a state of crisis, thus families should 
continue to be triaged for face-to-face support, where this is indicated.

Although many practitioners went above and beyond to find innovative solutions to care for bereaved parents, they also indicated concerns about the impact of the pandemic on their ability to provide best practice bereavement care to families. Health care providers are at an increased risk of experiencing their own grief at this time resulting from moral distress related to ethical decisions and isolation from their own personal support systems [11]. It is critical for practitioners to engage in selfcare and have access to appropriate resources and services. Adequate supervision and support is even more crucial at this time [11].

\section{Strengths and limitations}

To our knowledge, the impacts of COVID-19 on care following the death of a baby have not been explored. This study provides an early snapshot of practice adaptations. Although the study sample was relatively small, respondents were members of an expert group who were well-placed to provide on-the-ground insights into changes in care practices occurring across Australia. Being part of a perinatal bereavement care network meant that all had a particular interest in the topic and their experiences may differ from those from other settings. There is a need for improved, COVID-specific knowledge to enhance support and empowerment and prevent negative health outcomes, such as prolonged grief disorder. Service adaptations reported in this paper have underscored some important implications for practice of respectful and supportive perinatal bereavement care.

These include:

- Where possible deliver sad news and provide care with an appropriate level of PPE while recognising the need for communication adjustments

- Find ways to facilitate the involvement of partners, family members, and other support persons, including community elders, spiritual leaders and interpreter services according to parents' needs and wishes

- Continue to triage and assess needs for face-to-face consultation for each family

- Advocate for "compassionate allowances" to ensure the availability of support for those in high distress or crisis, while ensuring safety protocols

- Use strategies to enhance sensitive and compassionate communication via telehealth and consider ways to compensate for the loss of non-verbal cues
- Ensure private spaces are available for consultation with bereaved families and re-arrange spaces to allow for physical distancing and virtual communication

- Communicate openly and in a timely way with parents regarding decisions they need to make including any limitations due to COVID-19, so they have opportunities to ask questions and discuss options

- Make cold cots available and use them effectively to facilitate the time parents can spend with their baby and to extend time for decision-making

- Support parents to engage in memory-making practices and share responsibility as needed for practices affected by COVID-19 (e.g., taking photographs)

- Link parents with funeral agencies and parent support organisations regarding options for online support, memory-making and commemorative rituals

- Establish COVID-19 service specific guidelines for bereavement care to ensure effective communication between practitioners and parents and enhance continuity of care

- Provide professional development training in providing bereavement care in the context of COVID-19, including using telehealth and when wearing PPE

- Acknowledge the challenges for staff and prioritise adequate supervision, mentoring and support for their role

Perinatal bereavement care is a challenging area of practice and much variation exists in the care that parents receive [21]. COVID-19 presents new challenges and the risk of deepening an existing quality of care divide as well as providing opportunities for service innovations that promote high quality care for bereaved families.

Acknowledgments: We thank all members of the Stillbirth CRE perinatal bereavement care network for contributing their experiences and insights.

Research funding: This initiative falls within the work program of the Stillbirth CRE. Core funding to support the Stillbirth CRE is provided by the National Health and Medical Research Council (NHMRC). We gratefully thank the Mater Foundation for their contribution.

Author contributions: All authors have accepted responsibility for the entire content of this manuscript and approved its submission.

Competing interests: Authors state no conflict of interest. Informed consent: Informed consent to participate was implied by return of a completed online survey form.

Ethical approval: The local Institutional Review Board deemed the study exempt from review. 


\section{References}

1. Department of Health. COVID-19 health alert. [Internet]; 2021. cited 2022 Jan 13. Available from: https://www.health.gov.au/ news/health-alerts/novel-coronavirus-2019-ncov-healthalert\#government-response [Accessed 13 Jan 2022].

2. Townsend R, Chmielewska B, Barratt I, Kalafat E, van der Meulen J, Gurol-Urganci I, et al. Global changes in maternity care provision during the COVID-19 pandemic: a systematic review and metaanalysis. EClinicalMedicine 2021;37:100947.

3. Wilson AN, Sweet L, Vasilevski V, Hauck Y, Wynter K, Kuliukas L, et al. Australian women's experiences of receiving maternity care during the COVID-19 pandemic: a cross-sectional national survey. Birth 2021;49:30-9.

4. Meaney S, Leitao S, Olander EK, Pope J, Matvienko-Sikar K. The impact of COVID-19 on pregnant womens' experiences and perceptions of antenatal maternity care, social support, and stress-reduction strategies. Women Birth 2021. https://doi.org/ 10.1016/j.wombi.2021.04.013.

5. Ravaldi C, Wilson A, Ricca V, Homer C, Vannacci A. Pregnant women voice their concerns and birth expectations during the COVID-19 pandemic in Italy. Women Birth 2021;34:335-43.

6. Sweet L, Bradfield Z, Vasilevski V, Wynter K, Hauck Y, Kuliukas L, et al. Becoming a mother in the 'new' social world in Australia during the first wave of the COVID-19 pandemic. Midwifery 2021; 98:102996.

7. Vasilevski V, Sweet L, Bradfield Z, Wilson AN, Hauck Y, Kuliukas L, et al. Receiving maternity care during the COVID-19 pandemic: experiences of women's partners and support persons. Women Birth 2021. https://doi.org/10.1016/j.wombi.2021.04.012 [Epub ahead of print].

8. Campbell-Jackson L, Horsch A. The psychological impact of stillbirth on women: a systematic review. Illn Crises Loss 2014;22:237-56.

9. Gold KJ, Leon I, Boggs ME, Sen A. Depression and posttraumatic stress symptoms after perinatal loss in a population-based sample. J Wom Health 2016;25:263-9.

10. Heazell AE, Siassakos D, Blencowe H, Burden C, Bhutta ZA, Cacciatore J, et al. Stillbirths: economic and psychosocial consequences. Lancet 2016;387:604-16.

11. Wallace CL, Wladkowski SP, Gibson A, White P. Grief during the COVID-19 pandemic: considerations for palliative care providers. J Pain Symptom Manag 2020;60:e70-6.

12. Furtado-Eraso $\mathrm{S}$, Escalada-Hernández $\mathrm{P}$, Marín-Fernández $\mathrm{B}$. Integrative review of emotional care following perinatal loss. West J Nurs Res 2021;43:489-504.
13. Inati V, Matic M, Phillips C, Maconachie N, Vanderhook F, Kent AL. A survey of the experiences of families with bereavement support services following a perinatal loss. Aust N Z J Obstet Gynaecol 2018;58:54-63.

14. Chmielewska B, Barratt I, Townsend R, Kalafat E, van der Meulen J, Gurol-Urganci I, et al. Effects of the COVID-19 pandemic on maternal and perinatal outcomes: a systematic review and metaanalysis. Lancet Global Health 2021;9:e759-72.

15. Harrop EJ, Goss S, Farnell DJ, Longo M, Byrne A, Barawi K, et al. Support needs and barriers to accessing support: baseline results of a mixed-methods national survey of people bereaved during the COVID-19 pandemic. 2021 medRxiv. Available from: https://www.medrxiv.org/content/10.1101/2021.06.11. 21258575v1.full.pdf.

16. Miller M, Iyer DD, Hawkins C, Freedle A. The Impact of COVID-19 Pandemic on Women's Adjustment Following Pregnancy Loss: Brief Report. Available from: https://www.lindenwood.edu/ files/resources/pregnancy-loss-covid-19.pdf [Accessed 2 Aug 2021].

17. Flenady V, Oats J, Gardener G, Masson V, McCowan L, Kent A, et al. Clinical Practice Guideline for Care Around Stillbirth and Neonatal Death. Version 3.4. NHMRC Centre of Research Excellence in Stillbirth; 2020. Available from: https://stillbirthcre.org.au/wp-content/uploads/2021/03/ Clinical-Practice-Guidelines-for-Care-Around-Stillbirth-andNeonatal-Death2-2.pdf.

18. Boyle FM, Horey D, Middleton PF, Flenady V. Clinical practice guidelines for perinatal bereavement care-an overview. Women Birth 2020;33:107-10.

19. Pearce C, Honey JR, Lovick R, Creamer NZ, Henry C, Langford A, et al. 'A silent epidemic of grief': a survey of bereavement care provision in the UK and Ireland during the COVID-19 pandemic. BMJ Open 2021;11:e046872.

20. Taylor A, Caffery LJ, Gesesew HA, King A, Bassal AR, Ford $\mathrm{K}$, et al. How Australian health care services adapted to telehealth during the COVID-19 pandemic: a survey of telehealth professionals. Front Public Health 2021; 9:121.

21. Horey D, Boyle FM, Cassidy J, Cassidy PR, Erwich JJ, Gold KJ, et al. Parents' experiences of care offered after stillbirth: an international online survey of high and middle-income countries. Birth 2021;48:366-74.

Supplementary Material: The online version of this article offers supplementary material (https://doi.org/10.1515/.jpm-2021-0441). 